03

\title{
Исследование плазмодинамических процессов наносекундного диапазона при формировании ударных волн от импульсных разрядов
}

\author{
(С) И.А. Дорощенко, И.А. Знаменская, А.Ю. Кузнецов, И.В. Мурсенкова, Н.Н. Сысоев
}

Московский государственный университет им. М.В. Ломоносова,

119234 Москва, Россия

e-mail: doroshchenko93@gmail.com

(Поступило в Редакцию 13 июля 2017 г.)

\begin{abstract}
Динамика свечения плазмы импульсных разрядов - скользящего поверхностного и комбинированного объемного разряда с плазменными электродами - исследована в наносекундном временно́м диапазоне $(100-12000 \mathrm{~ns})$ в неподвижном воздухе и в потоках за фронтом плоской ударной волны с числами Маха 1.7-5.0 в канале ударной трубы. Проведено сравнение временнб́х характеристик свечения, спектров излучения и тока разрядов в воздухе в диапазоне давлений 5-150 Torr, импульсном напряжении $20-30 \mathrm{kV}$, токе $\sim 1 \mathrm{kA}$. Показано, что время протекания тока при различных условиях не превышает $400 \mathrm{~ns}$, a длительность свечения может достигать нескольких микросекунд. Показано, что в результате энерговклада вблизи фронта плоской ударной волны происходит распад разрывов с образованием ударных волн и контактных поверхностей. Проведено сопоставление положения областей свечения плазмы с положениями поверхностей разрыва газодинамических параметров в потоке, рассчитанных численно.
\end{abstract}

DOI: 10.21883/JTF.2018.05.45895.2435

\section{Введение}

Разряды наносекундной длительности, широко исследуемые в последнее время, используются, в частности, для воздействия на газодинамические течения [14]. Особенностью таких разрядов является изменение состояния газа за короткое время протекания тока разряда и его быстрый нагрев в результате импульсного энерговклада. Часть электрической энергии, переходящая в тепловую энергию в микросекундном интервале времени после разряда, зависит от параметров разряда и свойств среды $[1,2,4,5]$. Газодинамические параметры течения зависят от мощности разряда и геометрии области энерговклада, взаимодействующей с потоком [5]. Инициирование горения с помощью плазмы основано на генерации активных частиц в плазменном объеме и быстром нагреве газа [6]. Оптимизация параметров плазмы для задач плазменной газодинамики осуществляется путем сокращения рабочего цикла разряда, позволяющего избежать развития неустойчивостей. При инициировании импульсных разрядов в высокоскоростных потоках газа определяющими механизмами воздействия на течение являются тепловой (нагрев газа) $[1,2]$ и ударно-волновой $[2,4]$. Ударные волны, возникающие в результате резкого изменения состояния среды, могут существенно влиять на газодинамический поток. Интенсивность этих ударных волн и их динамика зависят от процессов, происходящих на начальной стадии формирования ударно-волнового течения после инициировании разряда.

Однородный объемный энерговклад в газ (поток газа) достигается при организации объемного разряда в диффузной форме [7,8]. Комбинированный объемный разряд с плазменными электродами исследовался в неподвижном воздухе и в газодинамическом потоке с плоской ударной волной [8]. Длительность свечения разряда в неподвижном воздухе зависела от напряжения на разрядном промежутке и давления воздуха и не превышала $400 \mathrm{~ns}$; при взаимодействии с плоской ударной волной длительность излучения в области фронта могла превышать $2 \mu \mathrm{s}$. Скользящий поверхностный разряд (плазменный лист), состоящий из параллельных скользящих по поверхности диэлектрика каналов, образует плазменный слой толщиной $\sim 0.5 \mathrm{~mm}$ около поверхности диэлектрика [2-4]. Он позволяет эффективно воздействовать на пристеночные газодинамические течения, так как развивается в тонком слое газа и обеспечивает значительный удельный энерговклад.

Присутствие ударных волн в разрядном объеме может приводить к изменению режима протекания тока разряда, пространственного распределения заряженных частиц и структуры излучения $[8,9]$. При инициировании импульсного разряда в потоке газа с ударной волной на фронте ударной волны возникают условия распада разрыва $[10,11]$. В то же время влияние газоразрядной плазмы на ударную волну может приводить к ее ускорению, ослаблению интенсивности, расширению фронта $[9,12,13]$.

При моделировании взаимодействия разрядов наносекундной длительности с потоками газа наиболее эффективным является рассмотрение разряда как источника энергии, мгновенно вкладываемой в поток. Предполагается, что электрическая энергия переходит во внутреннюю энергию газа за достаточно короткий по сравнению с характерными временами движения газодинамических 
возмущений промежуток времени $[14,15]$. Численное моделирование влияния энерговклада на поток перед обтекаемым объектом и на его боковой поверхности с использованием двумерных уравнений Навье-Стокса и SST-модели (Shear Stress Transport - модель переноса сдвиговых напряжений) турбулентности показало, что при определенных режимах энерговклад перед обтекаемым телом может уменьшить волновое сопротивление [14]. Образование ударных волн в результате оптического пробоя моделировалось сферически симметричной областью энерговклада [11], а энерговклад при моделировании стримерного разряда в воздушном промежутке имел цилиндрическую симметрию [15]. Одним из основных результатов данных работ являлось определение доли энергии разряда, которая была затрачена на образование ударных волн, т.е. была связана с быстрым изменением термодинамических параметров среды.

Численное моделирование газодинамических процессов при локализации импульсного объемного разряда перед фронтом плоской ударной волны проводилось в рамках математической модели нестационарных двумерных уравнений Эйлера с помощью обобщенной разностной схемы Годунова [16]. В расчет включался мгновенный энерговклад как от вспомогательных поверхностных разрядов, так и от объемного разряда. В первые микросекунды после воздействия разряда на фронт исходной ударной волны возникала система вертикальных разрывов, которые соответствуют аналитическому описанию одномерного течения после распада разрыва. Распад разрыва на фронте исходной ударной волны инициирует две ударные волны, между которыми находится контактная поверхность. Интенсивности этих газодинамических разрывов зависят от числа Маха исходной ударной волны, начального давления перед фронтом и мгновенного энерговклада перед фронтом. Так как энерговклад вблизи поверхности значительно превышает энерговклад в объемной части, на границе приповерхностных областей формируются ударные волны, движущиеся к плоскости симметрии течения. Таким образом, течение является двумерным. Сравнение теневых изображений с численным расчетом показало хорошее соответствие ударно-волновых конфигураций. Было также показано, что профили газодинамических параметров слабо меняются в случае мгновенного и распределенного по времени энерговклада (до $200 \mathrm{~ns}$ ), что дает возможность использовать в расчетах модель мгновенного энерговклада [16].

Нагрев газа при импульсном энерговкладе - одна из основных характеристик, определяющих влияние разрядов на газодинамические течения. Достаточно большая доля электрической энергии напрямую переходит в поступательные степени свободы молекул газа $(\sim 10-60 \%)[1,2,4,10,17,18]$. Большая часть электрической энергии в разрядах в воздухе идет на возбуждение колебательных и электронных степеней свободы молекул [18]. Время колебательно-поступательной релакса- ции достаточно велико (больше $10^{-4} \mathrm{~s}$ ), поэтому с точки зрения газодинамики существенна только часть энерговклада, приводящая к быстрому нагреву среды $[16,18]$.

Целью настоящей работы был анализ динамики свечения плазмы импульсного поверхностного разряда и комбинированного объемного разряда с плазменными электродами в покоящемся воздухе и в высокоскоростных потоках с фронтом ударной волны на основе регистрации излучения с помощью электронно-оптических камер БИФО К008 и К011 [8] в фотохронографическом и в 9-кадровом режиме соответственно. Особенностью плазмодинамических процессов при временах до $5 \mu \mathrm{s}$ после инициирования разряда наносекундной длительности является наличие рекомбинирующей и релаксирующей плазмы в разрядной области в течение нескольких микросекунд после окончания тока разряда, что при взаимодействии с газодинамическими разрывами может приводить к увеличению интенсивности и длительности послесвечения $[8,19]$. Динамика ударных волн после разряда исследовалась методом высокоскоростной теневой визуализации.

\section{Экспериментальная установка и условия проведения экспериментов}

Эксперименты проводились на установке, состоящей из ударной трубы и разрядной камеры с каналом сечением $24 \times 48 \mathrm{~mm}^{2}$ [2,8] (рис. 1). При приложении импульсного напряжения $20-30 \mathrm{kV}$ к системе электродов на верхней и нижней стенках разрядной камеры на расстоянии $24 \mathrm{~mm}$ друг от друга формировались скользящие поверхностные разряды площадью $30 \times 100 \mathrm{~mm}^{2}$ (плазменные листы) $[2,4]$. При инициировании объемного разряда они обеспечивали предыонизацию объема и служили электродами объемного разряда.

Кварцевые стекла, служащие боковыми стенками разрядной камеры, позволяли осуществлять оптическую регистрацию процессов в разрядной камере (рис. 1,2). Развертки свечения разрядов регистрировались камерой БИФО К008 в при различных режимах инициирования, время разверток составляло от $200 \mathrm{~ns}$ до $2 \mu \mathrm{s}$. С помощью камеры БИФО К011 регистрировались 9-кадровые изображения свечения разрядов с экспозицией $100-300 \mathrm{~ns}$ и межкадровым интервалом от $100 \mathrm{~ns}$. Камера К008 регистрировала излучение разряда, попадающего в щель шириной $100 \mu \mathrm{m}$. Щель камеры К008 располагалась при исследовании объемного разряда вдоль осей $O X$ или $O Y$, а при исследовании скользящего поверхностного разряда - вдоль оси $O X$ под небольшим углом наклона к плоскости разряда (перпендикулярно каналам разряда) (рис. 2). Спектральный диапазон чувствительности камер составлял $370-850 \mathrm{~nm}$. Одновременно регистрировалось интегральное излучение разряда, анализировался спектральный состав излучения и осциллографировался ток разряда. 


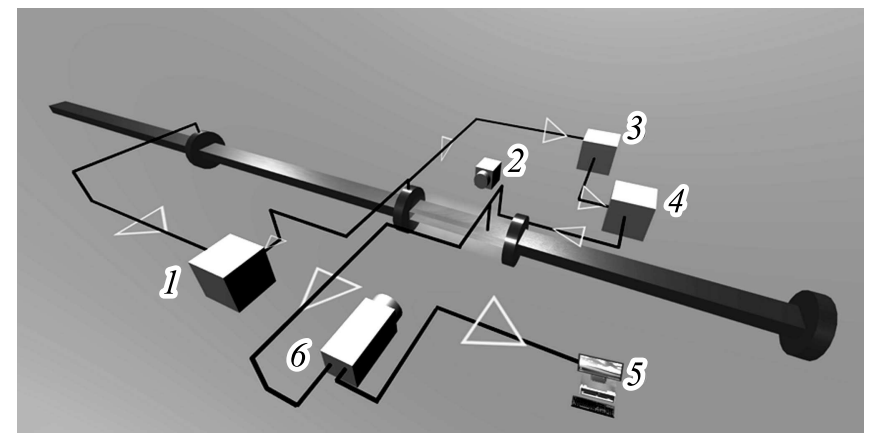

Рис. 1. Схема экспериментальной установки и диагностической аппаратуры: 1 - осциллограф, 2 - фотоаппарат, 3 генератор импульсов, 4 - блок запуска разряда, 5 - компьютер, 6 - высокоскоростная электронно-оптическая камера.

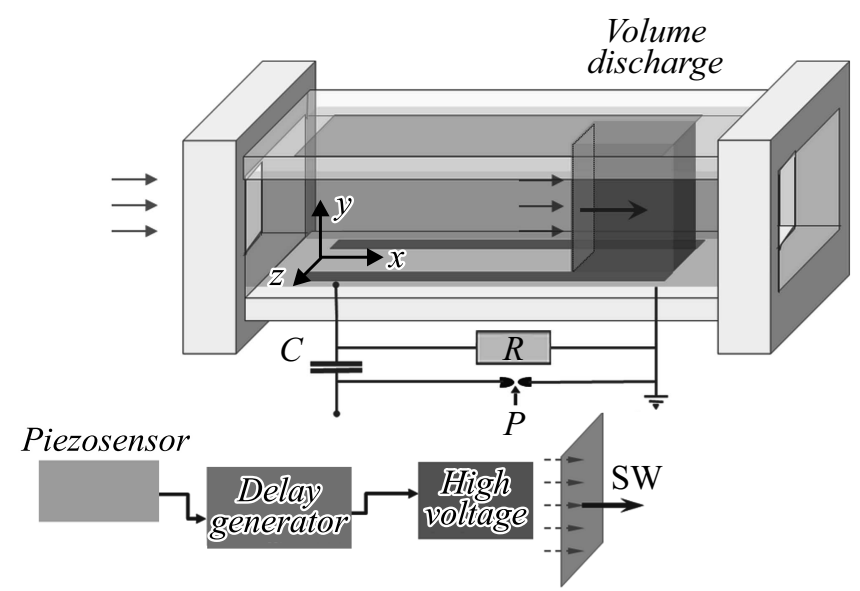

Рис. 2. Разрядная камера и порядок синхронизации процессов при нахождении фронта плоской ударной волны в разрядном объеме.

Комбинированный объемный разряд инициировался в разрядной камере в неподвижном воздухе и в потоках с плоской ударной волной при различных положениях фронта ударной волны относительно края разрядного объема. Давление воздуха в экспериментах варьировало от 5 до 300 Torr, числа Маха ударных волн изменялись в пределах 1.7-5.0. Импульсное напряжение составляло $20-30 \mathrm{kV}$, ток разрядов достигал $1 \mathrm{kA}$. Протяженность разрядной области вдоль направления движения ударной волны составляла $10 \mathrm{~cm}$; за нулевое значение координаты $x$ принималось начало электродов (рис. 1). Таким образом, положение фронта ударной волны внутри разрядного объема соответствовало $x \leq 10 \mathrm{~cm}$, а его нахождение за пределами разрядного объема $x>10 \mathrm{~cm}$. За время протекания тока разряда фронт ударной волны смещался не более чем на $0.5 \mathrm{~mm}$. Синхронизация запуска разряда с движением ударной волны осуществлялась от сигналов пьезоэлектических датчиков давления в канале ударной трубы.
По разверткам свечения строились зависимости интенсивности свечения разрядов от времени как вдоль отдельных линий, так и усредненные по выбранной области. Определялись полная длительность разряда и времена затухания свечения при разных начальных условиях в разрядной камере. По 9-кадровым изображениям анализировалось пространственное распределение свечения.

Одновременно регистрировались спектры излучения спектрометром AvaSpec-2048FT (диапазон длин волн 200-1100 nm), ток разряда с помощью малоиндуктивного шунта специальной конструкции, фотоизображения свечения фотокамерой Canon EOS 550D. Скорость ударных волн измерялась базовым методом по сигналам пьезоэлектрических датчиков давления в канале ударной трубы, синхронизация процессов в экспериментах осуществлялась также с помощью этих сигналов.

Проводилась теневая визуализация газодинамического поля течения после разряда на основе высокоскоростной цифровой камеры Photron Fastcam SA5 с частотой кадров до $750000 \mathrm{fps}$ и временем экспозиции $1 \mu \mathrm{s}$. Оптическая система теневого зондирования формировала излучение полупроводникового лазера с длиной волны $532 \mathrm{~nm}$ в плоскопараллельный пучок и направляла его перпендикулярно стеклам разрядной камеры. Важным преимуществом высокоскоростной съемки явилась возможность проследить эволюцию ударно-волновой структуры в случае каждого конкретного эксперимента, поскольку структура разряда, как правило, отличается в каждом случае инициирования разряда и соответственно отличается эволюция ударно-волновой конфигурации.

\section{Динамика излучения разрядов в неподвижном воздухе}

Спектральные исследования излучения разрядов показали, что основной вклад в излучение дает вторая положительная система азота, соответствующая переходам $C^{3} \Pi_{u} \rightarrow B^{3} \Pi_{g}(281-498 \mathrm{~nm}) \quad[8,19]$. Фотокамера и электронно-оптические камеры регистрируют часть этого спектра излучения.

Время протекания тока объемного и поверхностного разрядов при различных условиях не превышает $400 \mathrm{~ns}$, а длительность свечения зависит от состояния среды и структуры потока и может достигать нескольких микросекунд. Длительность тока разрядов в неподвижном воздухе - около $300 \mathrm{~ns}$, и основная часть энерговклада приходится на первый полупериод тока ( 150 ns) $[2,8]$.

На рис. 3 показаны фотоизображения свечения скользящих поверхностных разрядов на верхней и нижней стенках разрядной камеры, 9-кадровые изображения свечения и развертка свечения в неподвижном воздухе при давлении 150 Torr. Видно, что область разряда состоит из параллельных каналов разной интенсивности, развивающихся за время $\sim 30$ ns. Полная длительность свечения диффузных слабосветящихся каналов не превышает 
$100 \mathrm{~ns}$ (рис. 3,b). Каналы повышенной интенсивности характеризуются более ярким и длительным (более $1 \mu \mathrm{s}$ ) свечением.

В отсутствие газодинамического потока излучение объемной фазы комбинированного разряда достаточно однородно [8]. Полученные в результате обработки разверток экспериментальные зависимости интенсивности излучения от времени для объемного разряда и диффузных каналов поверхностного разряда в неподвижном воздухе имеют характерную куполообразную форму с плавным спадом интенсивности, полная длительность этого излучения не превышает $170 \mathrm{~ns}$. По этим зависимостям определялось время затухания свечения после прекращения тока разряда. Эта величина характеризует скорость процесса дезактивации электронных состояний молекул азота в плазме воздуха, так как спектр излучения разрядов определяется в основном полосами второй положительной системы азота.

Времена затухания излучения объемного разряда и диффузных каналов поверхностного разряда в неподвижном воздухе при давлении меньше 60 Torr составляют около $40 \mathrm{~ns}$ (рис. 4), что близко к времени жизни возбужденного уровня $C^{3} \Pi_{u}$ молекулы азота $(37 \mathrm{~ns}[18,19])$. С ростом давления время затухания свечения объемного разряда уменьшалось, что объясняется увеличением вероятности тушения рассматриваемого возбужденного состояния на молекулах азота и кислорода [19]. Время затухания диффузного свечения поверхностного разряда слабо изменяется при давлении до 60 Torr, а затем значительно возрастает. Время затухания свечения ярких каналов поверхностного разряда также возрастает с ростом давления. Это свидетельствует о различии в протекании кинетических процессов, приводящих к заселению и тушению излучающих состояний, в плазме поверхностного и объемного разрядов.
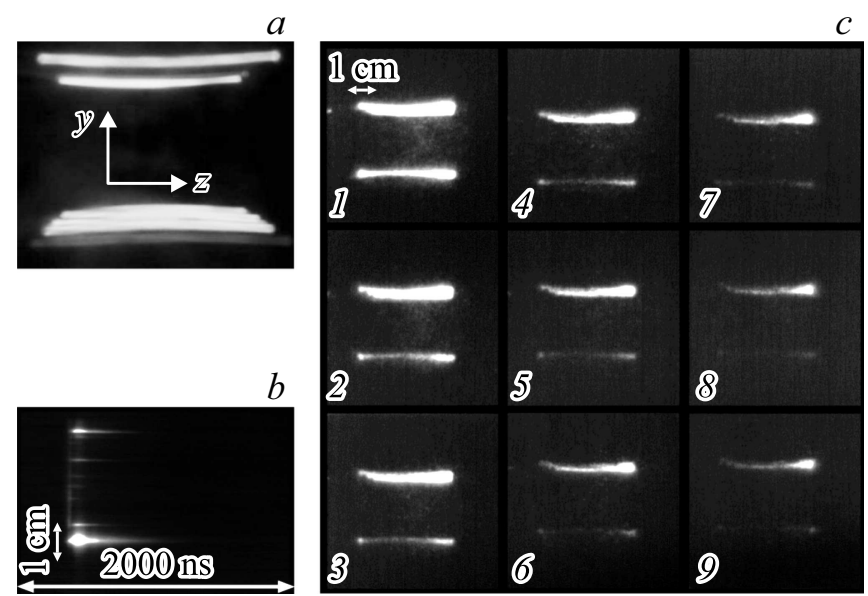

Pис. 3. Фотоизображение свечения $(a)$, развертка свечения при расположении щели камеры К008 вдоль оси $O X(b)$ и 9-кадровые изображения свечения скользящих поверхностных разрядов в неподвижном воздухе в плоскости $Y O Z$ (экспозиция $100 \mathrm{~ns}$, интервал между кадрами $100 \mathrm{~ns})(c)$. Давление 150 Torr, напряжение $25 \mathrm{kV}$.

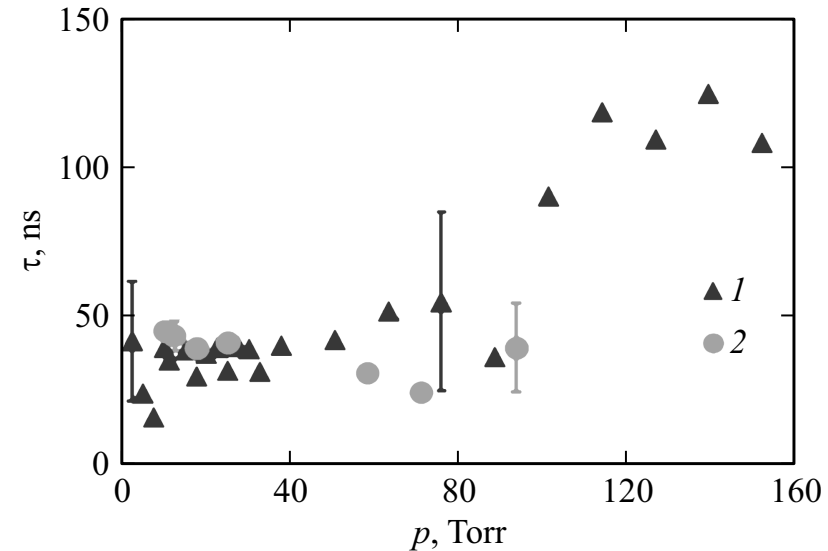

Рис. 4. Зависимость времени затухания свечения диффузной формы поверхностного разряда (1) и объемного разряда (2) от давления при напряжении $25 \mathrm{kV}$.

При инициировании скользящих поверхностных разрядов вблизи каналов повышенной яркости образуются наиболее интенсивные ударные волны $[2,17,20]$. Анализ формы фронта ударных волн и распределения скорости потока за ними показали, что мгновенный энерговклад, обеспечиваемый интенсивным каналом поверхностного разряда, однороден вдоль канала и приводит к образованию полуцилиндрической ударной волны взрывного типа за время менее $1 \mu$ s после разряда $[17,20]$.

\section{Плазмодинамические процессы при взаимодействии объемного разряда с плоской ударной волной}

Развитие импульсного разряда в неоднородном поле плотности происходит таким образом, что пробой начинается в области повышенного значения приведенной напряженности электрического поля $E / N(E-$ напряженность электрического поля, $N$ - концентрация молекул) [18]. Когда ударная волна находится внутри разрядного промежутка (первая конфигурация), разряд развивается перед фронтом ударной волны, в области низкого давления $[8,19]$ (рис. 5). Когда ударная волна выходит за пределы разрядного промежутка (вторая конфигурация) на расстояния до $1-1.5 \mathrm{~cm}$, свечение поверхностных разрядов приобретает П-образную форму, прилегая к фронту ударной волны, а свечение объемной части разряда сосредоточено в тонком слое в области фронта. Длительность тока разряда при этих условиях составляет около $500 \mathrm{~ns}$, а основной энерговклад в газ происходит в течение $400 \mathrm{~ns}$.

Во всех случаях при взаимодействии с плоской ударной волной свечение объемного и поверхностного разрядов усиливается в области фронта, и его длительность может превышать $2 \mu$ s $[8,19,21]$. 9-кадровые изображения, регистрируемые в течение $1700 \mathrm{~ns}$ после разряда, показали, что излучение разряда сосредоточено 


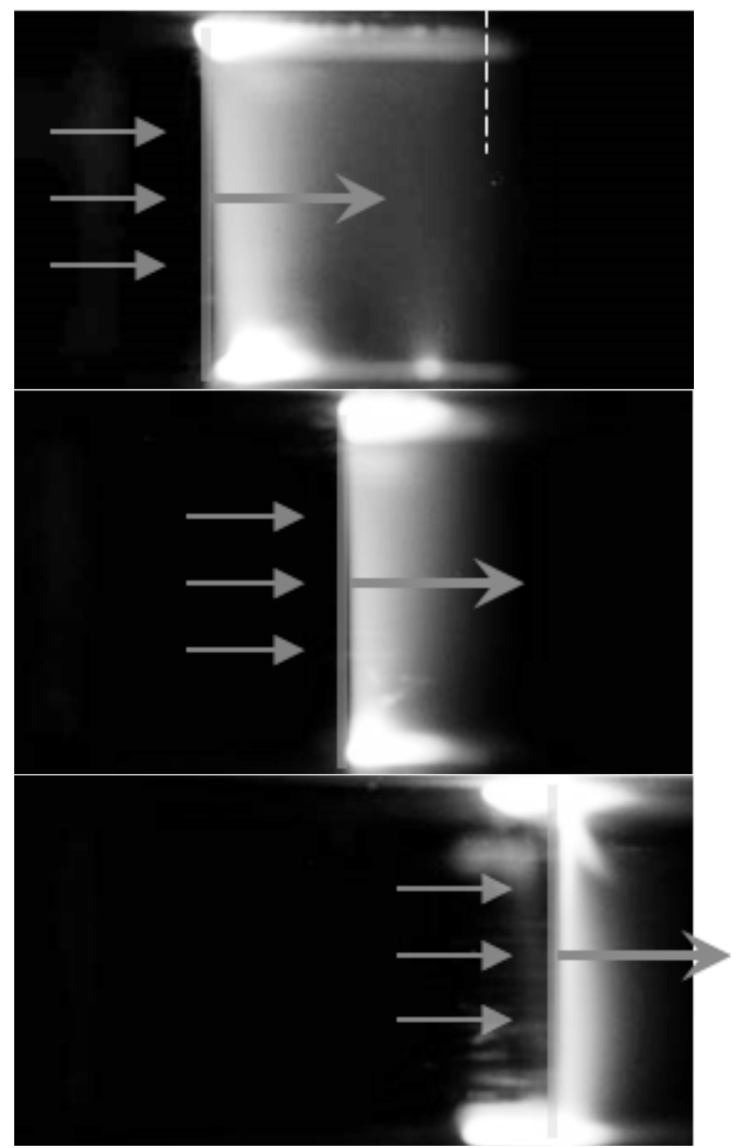

Рис. 5. Фотоизображения свечения объемного разряда с фронтом ударной волны при значениях $x=8,9$ и $10.7 \mathrm{~cm}$ (сверху вниз). Число Маха ударной волны 3.2, давление перед фронтом 20 Torr. Стрелки показывают направление движения ударной волны и потока за ней. Край разрядного промежутка отмечен штриховой линией. Напряжение $25 \mathrm{kV}$.

вблизи фронта ударной волны и его граница движется в том же направлении (рис. 6,a,c). Скорость движения светящейся зоны и характер свечения зависели от положения фронта ударной волны в разрядном объеме. Усиление интенсивности излучения вблизи фонта ударной волны сопровождалось длительным послесвечением области шириной 0.5-1.6 mm. Развертка свечения разряда с фронтом ударной волны внутри разрядного объема представляет собой узкую линию с наклоном, характеризующим скорость перемещения светящейся области (рис. $6, c, f)$.

Рис. $6, b$ показывает эволюцию свечения в случае первой конфигурации, когда фронт ударной волны находился внутри разрядного объема в момент инициирования разряда $(x=9 \mathrm{~cm}$ от левого края разрядного промежутка, рис. 6), а рис. 6, e- когда фронт ударной волны находился за пределами разрядного объема (вторая конфигурация, $x=10.4 \mathrm{~cm}$ ). Очевидны качественные различия в структуре образовавшейся области свечения в двух случаях. В первом случае объемный энерговклад в газ реализуется перед фронтом ударной волны, а поверхностный - на нижней и верхней плоскостях разрядного объема. Происходят распады газодинамических разрывов на левой границе, содержащей фонт ударной волны (слева - спутный поток, справа плазма разряда), и на правой границе (плазма разряда покоящийся воздух) (рис. 7). Одна из образовавшихся ударных волн движется вправо по области релаксирующей плазмы, сжимая ее. В случае второй конфигурации ток поверхностных разрядов сосредоточен в П-образных каналах, а объемного практически прижат к плоскости фронта ударной волны (рис. 6, d,e). Ударные волны после распада разрыва в этом случае взаимодействуют с тонким слоем газоразрядной плазмы.

Особенностью динамики излучения разряда при временах до $1700 \mathrm{~ns}$ после инициирования является движение ударных волн и контактных поверхностей по релаксирующей плазме, в которой термодинамические параметры могут меняться с течением времени. Так, на рис. $6, b, e$ первые два кадра свечения получены при протекании тока разряда ( $300 \mathrm{~ns})$. На следующих кадрах наблюдается послесвечение плазмы после прекращения тока разряда. Вблизи верхнего и нижнего плазменных листов интенсивность свечения выше интенсивности объемной части разряда.

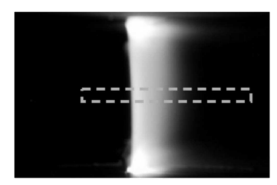

$a$

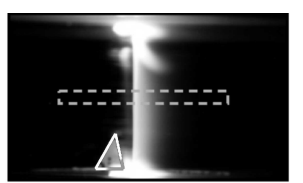

$d$
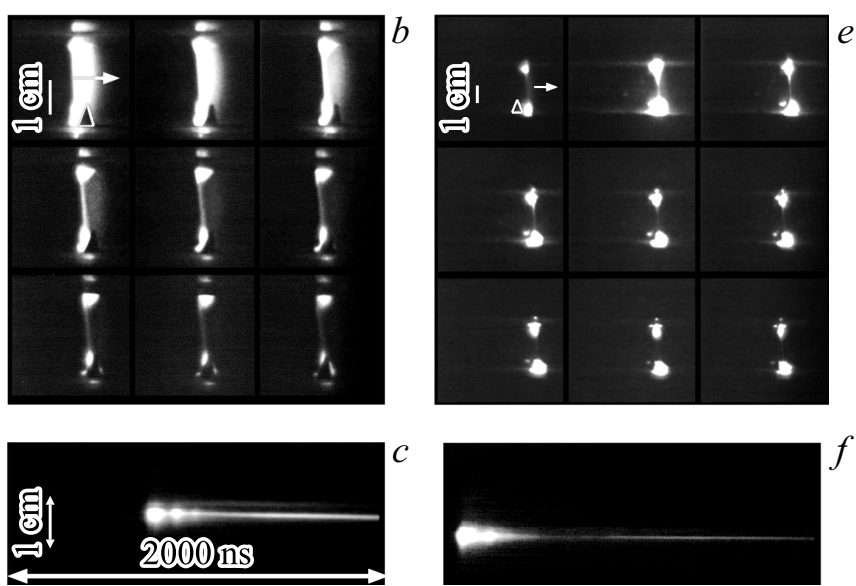

Рис. 6. Фотоизображения свечения объемного разряда при взаимодействии с фронтом ударной волны $(a, d)$; 9-кадровые изображения свечения $(b, e)$ (экспозиция $100 \mathrm{~ns}$, интервал между кадрами $100 \mathrm{~ns})$; развертки свечения $(c, f)$ (длительность развертки $2000 \mathrm{~ns})$. Изображения $a, b, d$, e получены в плоскости $X O Y$, положение щели камеры К008 вдоль оси $O X$ (показано штрихом на $a, d)$. Число Маха ударной волны 4.5 , давление перед фронтом 1 Torr, $x=9 \mathrm{~cm}(a-c)$; число Маха ударной волны 3.2, давление перед фронтом 20 Torr, $x=10.4 \mathrm{~cm}(d-f)$. Стрелки показывают направление движения ударной волны. Вершина треугольного маркера соответствует краю разрядного промежутка. Напряжение $25 \mathrm{kV}$. 


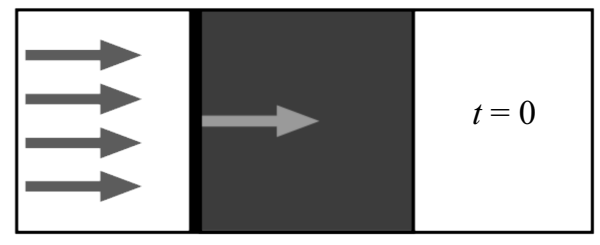

$S_{0}$
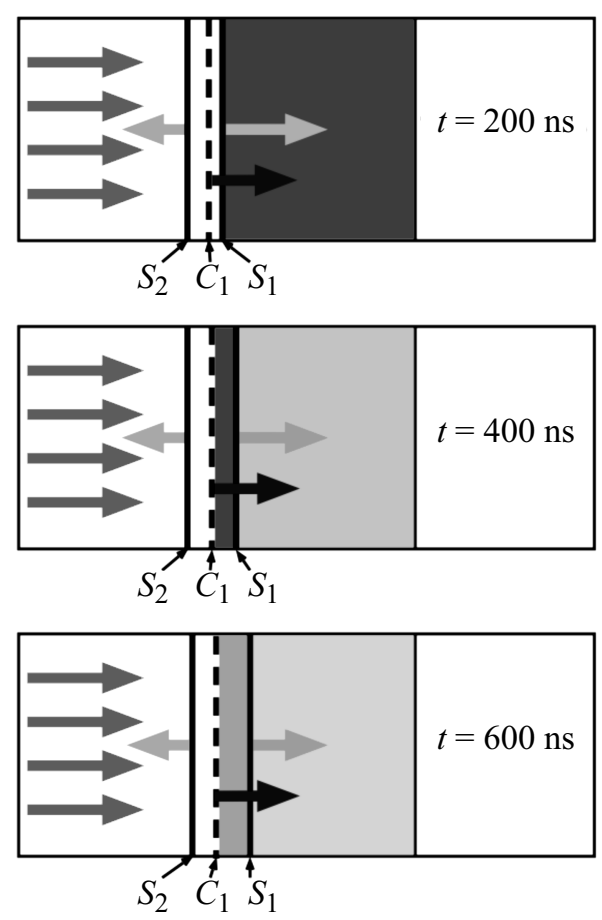
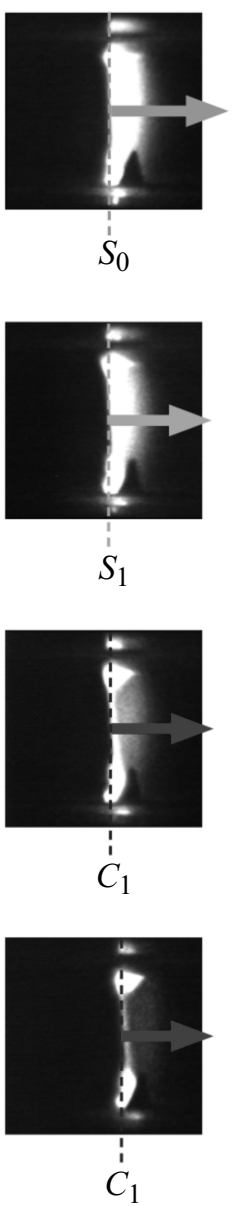

$C_{1}$
Рис. 7. Схема распада разрыва на фронте ударной волны при импульсном энерговкладе перед фронтом (слева) и изображения свечения области разряда (справа) ударных волн: $S_{1}$ и $S_{2}$ - ударные волны, $C_{1}$ - контактная поверхность.

При инициировании объемного разряда в присутствии плоской ударной волны происходит распад газодинамического разрыва [16], и одна из образовавшихся ударных волн движется по области плазмы, сжимая ее и образуя узкую область с повышенной концентрацией частиц в возбужденных состояниях [19]. По наборам полученных кадров и разверткам проводилось измерение скорости движения узкой области интенсивного свечения в центральной части течения. После прекращения тока разряда затухание свечения этой области носило двухступенчатый характер с определенным временны́м интервалом усиления излучения (рис. $6, c, f$ ). Для анализа свечения длительностью свыше $2000 \mathrm{~ns}$ после взаимодействия разряда с фронтом ударной волны рассматривалась кинетика возбужденных состояний молекулы азота [19]. Проведенный анализ показал, что наблюдаемая динамика излучения может быть обусловлена заселением излучающего состояния в условиях повышенной при ударном сжатии концентрации молекул азота в метастабильном состоянии $A^{3} \Sigma_{u}^{+}$. Характерные особенности пространственно-временного распределения излучения при взаимодействии разряда с фронтом ударной волны, очевидно, связаны с характером распада газодинамического разрыва на границе газ-плазма при импульсном энерговкладе в газ и последующим движением ударных волн, контактных разрывов и волн разрежения. Теневая визуализация позволила проследить динамику газодинамических разрывов после разряда [16]. На рис. 7 показана схема движения ударных волн $S_{1}$ и $S_{2}$ и контактной поверхности $C_{1}$ в последовательные моменты времени после распада разрыва на фронте ударной волны $S_{0}$. Исходная ударная волна $S_{0}$ и поток за ней движутся слева направо. Справа показаны соответствующие изображения свечения разрядной области.

При формировании ударных волн при распаде разрыва в первой конфигурации в начальный момент времени исходная ударная волна $S_{0}$ разделяет область газа в спутном потоке и газоразрядную плазму. Через $200 \mathrm{~ns}$ ударная волна распадается на три поверхности разрыва: ударные волны $S_{1}$ и $S_{2}$ и контактную поверхность $C_{1}$ между ними. С точки зрения газовой динамики за $200 \mathrm{~ns}$ эти поверхности разрыва проходят расстояния не более $0.1 \mathrm{~mm}$. Перед фронтом ударной волны $S_{1}$ на протяжении этого времени течет ток разряда, интенсивность свечения в этой области максимальна. В более поздние моменты времени (более $300 \mathrm{~ns}$ ) ток разряда и энерговклад отсутствуют. Ударная волна $S_{1}$ движется по релаксирующей неравновесной плазме, сжимая ее в узкую область, ограниченную ее фронтом и контактной поверхностью $C_{1}$. Излучение из этой области регистрируется на 9-кадровых изображениях в виде тонкой вертикальной полосы (рис. $6, b, e$, рис. 7 ) и на развертках (рис. 6, $c, f$ ).

\section{Численный расчет взаимодействия плоской ударной волной с областью объемного энерговклада}

Было проведено одномерное численное моделирование распада разрывов при мгновенном объемном энерговкладе перед фронтом ударной волны с целью определения скоростей движения газодинамических разрывов и сопоставления с динамикой свечения разряда. Так как поверхностный энерговклад в области плазменных листов выше объемного, распространяющиеся от него возмущения влияют на движение ударной волны и потока за ней $[10,16,21]$. Однако при малых временах после инициирования разряда, при формировании ударных волн, когда возмущения от плазменных листов не успевают дойти до центральной области канала, течение вблизи плоскости симметрии течения можно считать одномерным. В расчетной модели область плазмы соответствует газу с увеличенной внутренней энергией.

При различных положениях ударной волны внутри разрядного промежутка менялся только продольный размер области энерговклада (расстояние от фронта ударной волны до конца разрядного промежутка). Энергия, 

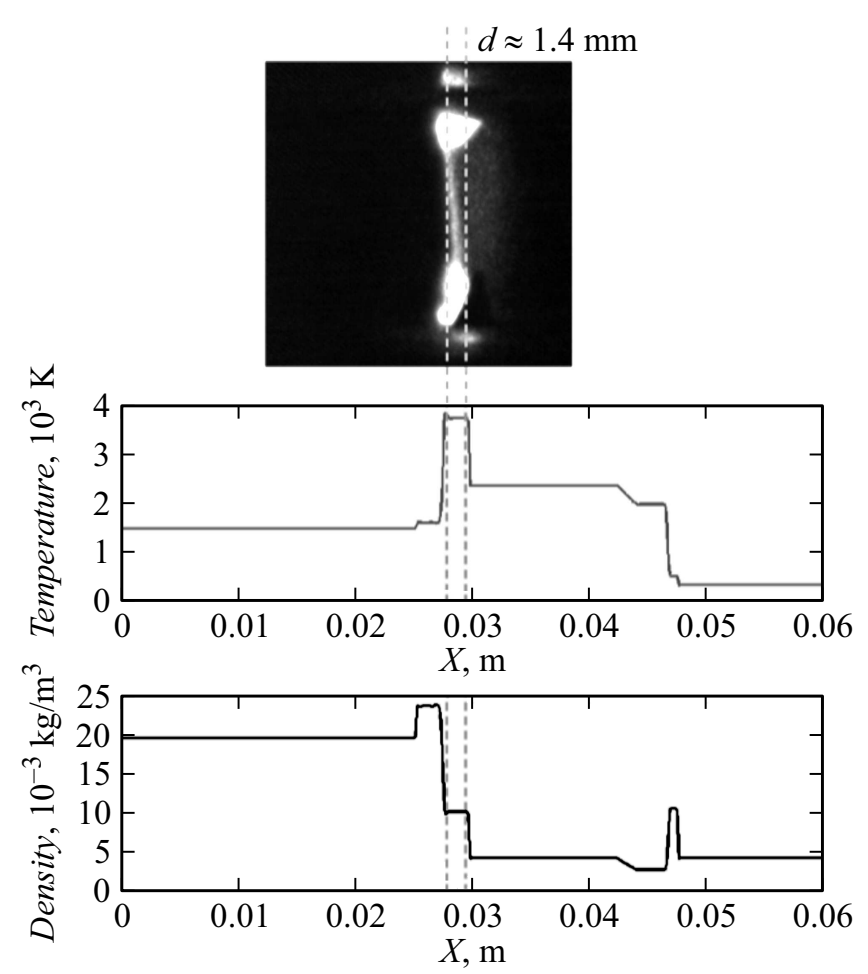

Рис. 8. Сравнение положения центральной области свечения (сверху) с положением скачков газодинамических параметров (снизу) через $1600 \mathrm{~ns}$ после энерговклада.

вкладываемая в газ перед фронтом ударной волны при исследуемых режимах, определялась ранее как часть электрической энергии, выделяющаяся при инициировании разряда $[2,4,10,17]$.

Решалась система уравнений Эйлера с помощью метода Годунова второго порядка [22]. В начальный момент времени задавались три области газа с различными значениями газодинамических параметров, на границах которых реализуются условия для распада разрывов: область энерговклада перед фронтом ударной волны (соответствующая области объемного разряда), справа от нее неподвижный воздух при начальных условиях эксперимента, и область слева от фронта ударной волны с параметрами, соответствующими параметрам ударно сжатого воздуха в спутном потоке за ударной волной (рис. 7). Начальная температура составляла 300 К, начальная плотность воздуха задавалась равной $2 \cdot 10^{-3} \mathrm{~kg} / \mathrm{m}^{3}$, что соответствовало условиям эксперимента, на рис. $6, a-c$. Энерговклад варьировался в зависимости от размера области энерговклада от $5 \cdot 10^{3}$ до $2.1 \cdot 10^{4} \mathrm{~J} / \mathrm{m}^{3}$. Показатель адиабаты воздуха считался постоянным и равным $\gamma=1.4$. Число Маха ударной волны изменялось в пределах 4.3-4.8.

Результаты расчета для момента времени $1600 \mathrm{~ns}$ после мгновенного энерговклада представлены на рис. 8 . На профилях температуры и плотности видно резкое изменение параметров слева и справа от области энерговклада, возникшее при распаде двух разрывов. Ширина расчетной области с повышенной температурой между фронтом ударной волны $S_{1}$ и контактной поверхностью $C_{1}$ оказалась близка к экспериментальной ширине области свечения в плоскости симметрии течения, равной $0.5-1.6 \mathrm{~mm}$ (рис. 8).

Сравнение положения и скоростей разрывов и зоны свечения показало, что в течение первых 300-400 ns после разряда левая граница области свечения совпадает с положением фронта ударной волны $S_{1}$. В более поздние моменты времени левая граница области свечения соответствует положению контактной поверхности $C_{1}$.

\section{Заключение}

Динамика излучения плазмы при формировании разрывов при инициировании скользящего поверхностного и комбинированного объемного разряда наносекундной длительности изучена в неподвижном воздухе и в присутствии плоской ударной волны с числами Маха 1.7-5.0 в канале ударной трубы. В пределах временного диапазона 100-12000 ns проведено сравнение временны́х характеристик свечения и тока разрядов в воздухе при давлениях 5-150 Torr. Время протекания тока при различных условиях не превышало $400 \mathrm{~ns}$, длительность свечения достигала нескольких микросекунд при разных условиях.

Исследованы плазмодинамические процессы при формировании ударных волн от поверхностного скользящего разряда и объемного разряда в двух конфигурациях при наличии ударной волны в разрядном объеме и при выходе из разрядного объема.

Анализ динамики свечения показал, что при инициировании объемного разряда в присутствии плоской ударной волны (распад газодинамического разрыва) одна из образовавшихся ударных волн движется по релаксирующей области плазмы, сжимая ее и образуя узкую светящуюся область с повышенной концентрацией частиц в возбужденных состояниях. Обнаружено, что если ударная волна находится за пределом разрядного промежутка на расстоянии до $1-1.5 \mathrm{~cm}$, свечение поверхностных разрядов приобретает П-образную форму, прилегая к фронту ударной волны, а свечение объемной части разряда сосредоточено в тонком слое в области фронта.

В результате сопоставления результатов экспериментального и численного исследования показано, что пространственно-временная структура свечения плазмодинамических структур после разряда наносекундной длительности определяется движением газодинамических разрывов. Таким образом, инициирование импульсного разряда в определенных режимах течения в канале и на поверхности позволяет контролируемо перераспределять ток разряда на основе формирования разрывов.

Работа выполнена при финансовой поддержке РФФИ (гранты 15-08-02417, 17-08-00560) и Программы развития МГУ до 2020 г. 


\section{Список литературы}

[1] Moreau E. // J. Phys. D. Appl. Phys. 2007. Vol. 40.

[2] Знаменская И.А., Латфуллин Д.Ф., Луцкий А.Е., Мурсенкова И.В., Сысоев Н.Н. // ЖТФ. 2007. Т. 77. Вып. 5. С. 10 18.

[3] Bayoda K.D., Benard N., Moreau E. // J. Appl. Phys. 2015. Vol. 118.

[4] Знаменская И.А., Латфуллин Д.Ф., Луцкий А.Е., Мурсенкова И.В. // Письма в ЖТФ. 2010. Т. 36. Вып. 17.

[5] Parisse J.D., Leger L., Depussay E., Lago V., Burtshell Y. // Phys. Fluids. 2009. Vol. 21. P. 106103.

[6] Adamovich I.V., Choi I., Jiang N., Kim J.-H., Keshav S., Lempert W.R., Mintusov E., Nishihara M., Samimy M., Uddi M. // Plasm. Sourc. Sci. Technol. 2009. Vol. 18. P. 034018

[7] Карлов Н.В., Кузьмин Г.П., Прохоров А.М. // Изв. АН СССР. Сер. физ. 1984. Т. 48. № 7. С. 1430.

[8] Архипов Н.О., Знаменская И.А., Мурсенкова И.В., Остапенко И.Ю. // Вестник МГУ. Сер. 3. Физика. Астрономия. 2014. № 1. C. 88-95.

[9] Лапушкина Т.А., Ерофеев А.В. // Письма в ЖТФ. 2015. Т. 41. Вып. 5. С. 35-41.

[10] Знаменская И.А., Коротеев Д.А., Попов Н.А. // Теплофизика высоких температур. 2005. Т. 43. № 5. С. 820-827.

[11] Zhang B., Ng H.D., Lee J.H.S. // Shock Waves. 2012. Vol. 22. P. 1-7

[12] Macheret S.O., Ionikh Y.Z., Chernysheva N.V., Yalin A.P., Martinelli L., Miles R.B. // Phys. Fluid. 2001. Vol. 13. N 9. P. 13.

[13] Барышников А.С., Басаргин И.В., Бобашев С.В., Монахов Н.А., Попов П.А., Сахаров В.А., Чистякова М.В. // Письма в ЖТФ. 2015. Т. 41. Вып. 15. С. 83-89.

[14] Kudryashov I.Yu., Lutsky A.E., Khankhasaeva Ya.V. // Mathematic. Model. Computer Simulations. 2016. Vol. 8. N 2. P. 207-218.

[15] Глушнева А.В., Савельев А.С., Сон Е.Е., Терешонок Д.В. // ЖТФ. 2015. Т. 85. Вып. 3. С. 153-155. (Glushneva A.V., Saveliev A.S., Son E.E., Tereshonok D. V. // Shock Waves. 2012. Vol. 22. Technical Physics. 2015. Vol. 60. N 3. P. 471473.)

[16] Znamenskaya I.A., Koroteev D.A., Lutsky A.E. // Phys. Fluid. 2008. Vol. 20. P. 056101-1-056101-6.

[17] Знаменская И.А., Луцкий А.Е., Мурсенкова И.В. // Письма в ЖТФ. 2004. Т. 30. Вып. 24. С. 38-42.

[18] Райзер Ю.П. Физика газового разряда. М.: Наука, 1987. $592 \mathrm{c}$.

[19] Кузнецов А.Ю., Мурсенкова И.В. // Прикладная физика. 2016. № 5. C. 16-21.

[20] Глазырин Ф.Н., Знаменская И.А., Мурсенкова И.В., Наумов Д.С., Сысоев Н.Н. // Письма в ЖТФ. 2016. Т. 42. Вып. 2. С. 16-22.

[21] Знаменская И.А., Мурсенкова И.В., Орлов Д.М., Сысоев Н.Н. // Письма в ЖТФ, 2007. Т. 33. Вып. 13. С. 72-77.

[22] Знаменская И.А., Иванов И.Э., Коротеева Е.Ю., Орлов Д.М. // Вестник Московского ун-та. Сер. 3: Физика. Астрономия. 2012. № 6. С. 81-86. 